\title{
In vitro insulin secretion by pancreatic tissue from infants with diazoxide-resistant congenital hyperinsulinism deviates from model predictions
}

\author{
Jean-Claude Henquin, ${ }^{1}$ Myriam Nenquin, ${ }^{1}$ Christine Sempoux, ${ }^{2}$ Yves Guiot, ${ }^{2}$ \\ Christine Bellanné-Chantelot, ${ }^{3}$ Timo Otonkoski, ${ }^{4}$ Pascale de Lonlay, ${ }^{5}$ \\ Claire Nihoul-Fékété, ${ }^{6}$ and Jacques Rahier ${ }^{2}$
}

\begin{abstract}
1 Unit of Endocrinology and Metabolism and 2Department of Pathology, Faculty of Medicine, University of Louvain, Brussels, Belgium. ${ }^{3}$ Department of Genetics, Hospital Pitié-Salpétrière, Paris, France. ${ }^{4}$ Research Programs Unit, Molecular Neurology, Biomedicum Stem Cell Centre, and Children's Hospital, University of Helsinki, Helsinki, Finland. ${ }^{5}$ Reference Centre of Metabolic Diseases, University Paris Descartes, Paris, France. ${ }^{6}$ Department of Pediatric Surgery, Hospital Necker-Enfants Malades, Paris, France.
\end{abstract}

\begin{abstract}
Congenital hyperinsulinism (CHI) is the major cause of persistent neonatal hypoglycemia. CHI most often occurs due to mutations in the $A B C C 8$ (which encodes sulfonylurea receptor 1 ) or KCNJ11 (which encodes the potassium channel Kir6.2) gene, which result in a lack of functional KATP channels in pancreatic $\beta$ cells. Diffuse forms of $\mathrm{CHI}(\mathrm{DiCHI})$, in which all $\beta$ cells are abnormal, often require subtotal pancreatectomy, whereas focal forms (FoCHI), which are characterized by localized hyperplasia of abnormal $\beta$ cells, can be cured by resection of the lesion. Here, we characterized the in vitro kinetics of insulin secretion by pancreatic fragments from $6 \mathrm{DiCHI}$ patients and by focal lesion and normal adjacent pancreas from 18 FoCHI patients. Responses of normal pancreas were similar to those reported for islets from adult organ donors. Compared with normal pancreas, basal insulin secretion was elevated in both FoCHI and DiCHI tissue. Affected tissues were heterogeneous in their secretory responses, with increased glucose levels often producing a rapid increase in insulin secretion that could be followed by a paradoxical decrease below prestimulatory levels. The KATP channel blocker tolbutamide was consistently ineffective in stimulating insulin secretion; conversely, the KATP channel activator diazoxide often caused an unanticipated increase in insulin secretion. These observed alterations in secretory behavior were similar in focal lesion and DiCHI tissue, and independent of the specific mutation in $A B C C 8$ or KCNJ11. They cannot be explained by classic models of $\beta$ cell function. Our results provide insight into the excessive and sometimes paradoxical changes in insulin secretion observed in CHI patients with inactivating mutations of KATP channels.
\end{abstract}

\section{Introduction}

Congenital hyperinsulinism (CHI) is the major cause of persistent hypoglycemia in newborns and infants $(1,2)$. The underlying genetic etiology and biochemical mechanisms are multiple, resulting in heterogeneous clinical presentation from relatively mild, medically responsive forms to severe forms requiring near total pancreatectomy. The most common and severe cases of $\mathrm{CHI}$ are caused by inactivating mutations in $A B C C 8(90 \%)$ and $K C N J 11$ $(10 \%)$ genes, which are both located on chromosome $11 \mathrm{p} 15$ and respectively encode sulfonylurea receptor 1 (SUR1) and Kir6.2, the regulatory and pore-forming subunits of ATP-sensitive $\mathrm{K}\left(\mathrm{K}_{\mathrm{ATP}}\right)$ channels in pancreatic $\beta$ cells (2-6). More than 150 mutations in $A B C C 8$ and about 25 mutations in KCNJ11 have been reported (6, 7), which cause defective channel trafficking to the plasma membrane or impairment of channel regulation by nucleotides.

Glucose control of insulin secretion is normally achieved through the interaction of triggering and amplifying pathways in $\beta$ cells (reviewed in ref. 8). $K_{\text {ATP }}$ channels play an essential role in the triggering pathway. When $\beta$ cells sense a rise in blood glucose, their metabolism accelerates, causing an increase in ATP and

Conflict of interest: The authors have declared that no conflict of interest exists. Citation for this article: J Clin Invest. 2011;121(10):3932-3942. doi:10.1172/JCI58400. a decrease in Mg-ADP concentrations in the cytosol, which close $\mathrm{K}_{\mathrm{ATP}}$ channels. As a consequence, the membrane depolarizes and voltage-gated $\mathrm{Ca}^{2+}$ channels open, allowing $\mathrm{Ca}^{2+}$ influx and leading to a rise in the cytosolic free $\mathrm{Ca}^{2+}$ concentration $\left(\left[\mathrm{Ca}^{2+}\right]_{c}\right)$ that triggers exocytosis of insulin granules. Simultaneously, glucose activates an amplifying pathway that does not elevate $\left[\mathrm{Ca}^{2+}\right]_{\mathrm{c}}$ further but augments the secretory response to high $\left[\mathrm{Ca}^{2+}\right]_{\mathrm{c}}$. Conversely, a fall in blood glucose is normally followed by opening of $\mathrm{K}_{\mathrm{ATP}}$ channels with membrane hyperpolarization, lowering of $\left[\mathrm{Ca}^{2+}\right]_{c}$, and cessation of insulin secretion.

Drugs that increase or lower $\beta$ cell $\left[\mathrm{Ca}^{2+}\right]_{\mathrm{c}}$ independently of metabolism reproduce the secretory changes mediated by the triggering pathway (9). Antidiabetic sulfonylureas augment insulin secretion by closing $\mathrm{K}_{\mathrm{ATP}}$ channels, whereas diazoxide inhibits insulin secretion by opening the channels. This explains the use of diazoxide as primary medical treatment of CHI (1). This approach is successful except in most patients with a mutation of $\mathrm{K}_{\mathrm{ATP}}$ channels, who therefore require other medical and dietary treatments and eventually surgical pancreatic resection in the most severe cases.

Histologically, 2 forms of diazoxide-resistant hyperinsulinism can be distinguished $(10,11)$. In diffuse forms of CHI (DiCHI), all $\beta$ cells in all islets are affected. The genetic cause is a recessive (more rarely dominant) mutation in $A B C C 8$ or $\operatorname{KCNJ11~(2,~6,~7,~}$ 
Table 1

Clinical and genetic characteristics of patients

\begin{tabular}{|c|c|c|c|c|c|c|}
\hline Case No. & $\begin{array}{l}\text { Months at } \\
\text { surgery }\end{array}$ & Post-op & Mutation Gene & Nucleotide level & Protein level & Impact on channel function (ref.) \\
\hline FoCHI1 & 5 & Cured & KCNJ11 Exon 1A & c.244_247dupAGCT & p.Trp83X & \\
\hline FoCHI2 & 7.5 & Cured & ABCC8 Exon 4 & c.560T>A & p.Val187Asp & $\begin{array}{l}\text { Intracellular retention }(58,59) \\
\text { No K-ATP current }(57)\end{array}$ \\
\hline FoCHI3 & 2 & Cured & ABCC8 Exon 4 & c.560T>A & p.Val187Asp & $\begin{array}{l}\text { Intracellular retention }(58,59) \\
\text { No K-ATP current }(57)\end{array}$ \\
\hline FoCHI4 & 2 & Cured & ABCC8 Exon 4 & c.560T>A & p.Val187Asp & $\begin{array}{l}\text { Intracellular retention }(58,59) \\
\text { No K-ATP current }(57)\end{array}$ \\
\hline FoCHI5 & 14 & Cured: 2 op & $A B C C 8$ Intron 4 & c. $580-1 \mathrm{G}>\mathrm{C}$ & p.? & \\
\hline FoCHI6 & 7 & Cured & ABCC8 Exon 5 & c. $683 \mathrm{G}>\mathrm{A}$ & p.Gly228Asp & Intracellular retention (60) \\
\hline FoCHI7 & 11 & Cured & ABCC8 Intron 7 & c. $1176+2 T>C$ & p.? & \\
\hline FoCHI8 & 9 & Cured: 3 op & ABCC8 Exon 12 & c. $1792 \mathrm{C}>\mathrm{T}$ & p.Arg598X & No K-ATP current (66) \\
\hline FoCHI9 & 3.5 & Cured & $A B C C 8$ Exon $12^{A}$ & c. $1817 \mathrm{G}>\mathrm{A}$ & p.? & \\
\hline FoCHI10 & 6 & Cured & ABCC8 Exon 15 & c. $2064 \mathrm{G}>\mathrm{A}$ & p.Trp688X & \\
\hline FoCHI11 & 5 & Cured & $A B C C 8$ Exon $22^{A}$ & c.2588_2591delATCT & p.His863fs & \\
\hline FoCHI12 & 2 & Cured: 2 op & $A B C C 8$ Intron 32 & c.3991+2_3991+15del14 & p.? & \\
\hline FoCHI13 & 2.5 & Cured & ABCC8 Exon 36 & c. 4325 delC & p.Pro1442fs & \\
\hline FoCHI14 & 8 & Cured & $A B C C 8$ Exon $36^{A}$ & c. $4354 \mathrm{~T}>\mathrm{C}$ & p.Trp1452Arg & \\
\hline FoCHI15 & 10 & Cured: 2 op & $A B C C 8$ Exon $36^{A}$ & c. $4359 \mathrm{G}>\mathrm{T}$ & p.Glu1453Asp & \\
\hline FoCHI16 & 10.5 & Cured & ABCC8 Exon 36 & c. $4408 \mathrm{G}>\mathrm{T}$ & p.Gly1470Val & \\
\hline FoCHI17 & 5 & Cured & ABCC8 Intron 36 & c. $4415-13 G>A$ & p.? & \\
\hline FoCHI18 & 6 & Cured & Unknown & Unknown & Unknown & \\
\hline DiCHI1 & 3 & Diabetes & $A B C C 8$ Exon 5 & c.683G>A; Homoz & p.Gly228Asp & Intracellular retention (60) \\
\hline DiCHI2 & 5 & Diabetes & ABCC8 Exon 9 & c.1420C>T; Homoz & p.GIn474X & \\
\hline DiCHI3 & 2.5 & Glucose intol. & $A B C C 8$ Intron $28^{A}$ & c.3561-3C>G; Homoz & p.? & $\begin{array}{l}\text { No K-ATP current, but rescue } \\
\text { by culture at } 25^{\circ} \mathrm{C}(67)\end{array}$ \\
\hline DiCHI4 & 6 & Diabetes: 2 op & ABCC8 Exon 34 & c. $4160 \mathrm{C}>\mathrm{T}$ & p.Ser1387Phe & $\begin{array}{l}84 \% \text { membrane expression } \\
\text { of defective channel (62) }\end{array}$ \\
\hline DiCHI5 & 7 & Hypos & ABCC8 Exon 37 & c.4480C >T; Homoz & p.Arg1494Trp & Intracellular retention (61) \\
\hline DiCHI6 & 18 & Diabetes & $\begin{array}{l}A B C C 8 \text { Exons } 28^{A} \\
\text { and } 37\end{array}$ & $\begin{array}{l}\text { c. } 3559 A>G \\
\text { c. } 4481 G>A\end{array}$ & $\begin{array}{l}\text { p.Arg1187Gly; } \\
\text { p.Arg1494Gln }\end{array}$ & \\
\hline
\end{tabular}

The mutation nomenclature is based on the reference sequences KCNJ11 NM_000525.3 and ABCC8 NM_000352.3 corresponding to the L72808 isoform $(1,582$ amino acids), which incorporates the extra serine residue in exon 17 (6). All mutations identified at heterozygous state with the exception of DiCHI1, -2 , -3 , and -5 (homozygous), and DiCHI6 (compound heterozygous). AMutations believed to be novel. References to the others in refs. 6 , 7 . Post-op, post-operative; glucose intol., glucose intolerant; homoz, homozygous; op, operations.

$12,13)$. In focal forms (FoCHI), a localized hyperplasia of abnormal $\beta$ cells is present within an otherwise normal pancreas. These focal lesions result from the coexistence of inherited and acquired events. Most often, the inherited event is a constitutional recessive paternal mutation in $A B C C 8$ or $K C N J 11$ that would remain silent alone. The acquired event is a somatic deletion of the corresponding maternal segment of chromosome $11 \mathrm{p} 15$, which leads to loss of heterozygosity (with isodisomy or duplication of the paternal mutated allele) $(14,15)$. The same $11 \mathrm{p} 15$ region also contains several imprinted genes involved in cell replication: the maternally expressed CDKN1C (p57) and H19, and the paternally expressed $I G F-I I$, which respectively inhibit and promote cell proliferation. The local $\beta$ cell hyperplasia is attributed to the imbalance between these genes $(16,17)$. Distinction between these 2 forms has major therapeutic implications: whereas medically unresponsive DiCHI usually requires near total pancreatectomy, FoCHI can be cured by a selective localized resection of the lesion $(18,19)$.

Patch-clamp studies (reviewed in ref. 5) have shown that $\beta$ cells, obtained after near total pancreatectomy of diazoxide-resistant DiCHI patients, have no or very few functional $\mathrm{K}_{\mathrm{ATP}}$ channels in their plasma membranes. They are depolarized, with variably elevated $\left[\mathrm{Ca}^{2+}\right]_{\mathrm{c}}$ in the presence of low glucose concentrations, and do not display changes in $\left[\mathrm{Ca}^{2+}\right]_{\mathrm{c}}$ upon application of high glucose concentrations, tolbutamide, or diazoxide $(20,21)$. Studies of 3 FoCHI cases showed that functional $\mathrm{K}_{\mathrm{ATP}}$ channels are absent from $\beta$ cells within the focal lesion and present and normally regulated in the adjacent pancreas (22). In vitro data on insulin secretion by $\mathrm{CHI}$ pancreas are scanty and sometimes controversial. Three studies were performed before the pathogenesis of the disease started to be understood. Islets isolated from 1 diazoxide-resistant CHI patient doubled insulin secretion in response to glucose (23). Islet cell clusters from 4 diazoxide-resistant DiCHI patients poorly responded to glucose but were stimulated by cAMP (24). Islet cell clusters from $4 \mathrm{DiCHI}$ patients were stimulated by cAMP, were insensitive to high glucose, and variably responded to other fuels while maintained in culture for 1-4 weeks (25). More recently, insulin secretion was studied in islets from 3 DiCHI patients lacking functional $\mathrm{K}_{\mathrm{ATP}}$ channels in their $\beta$ cells because of a mutation in $A B C C 8$. Tolbutamide and $\mathrm{KCl}$ were ineffective in low glucose conditions, but high glucose conditions were stimulatory. The effect 


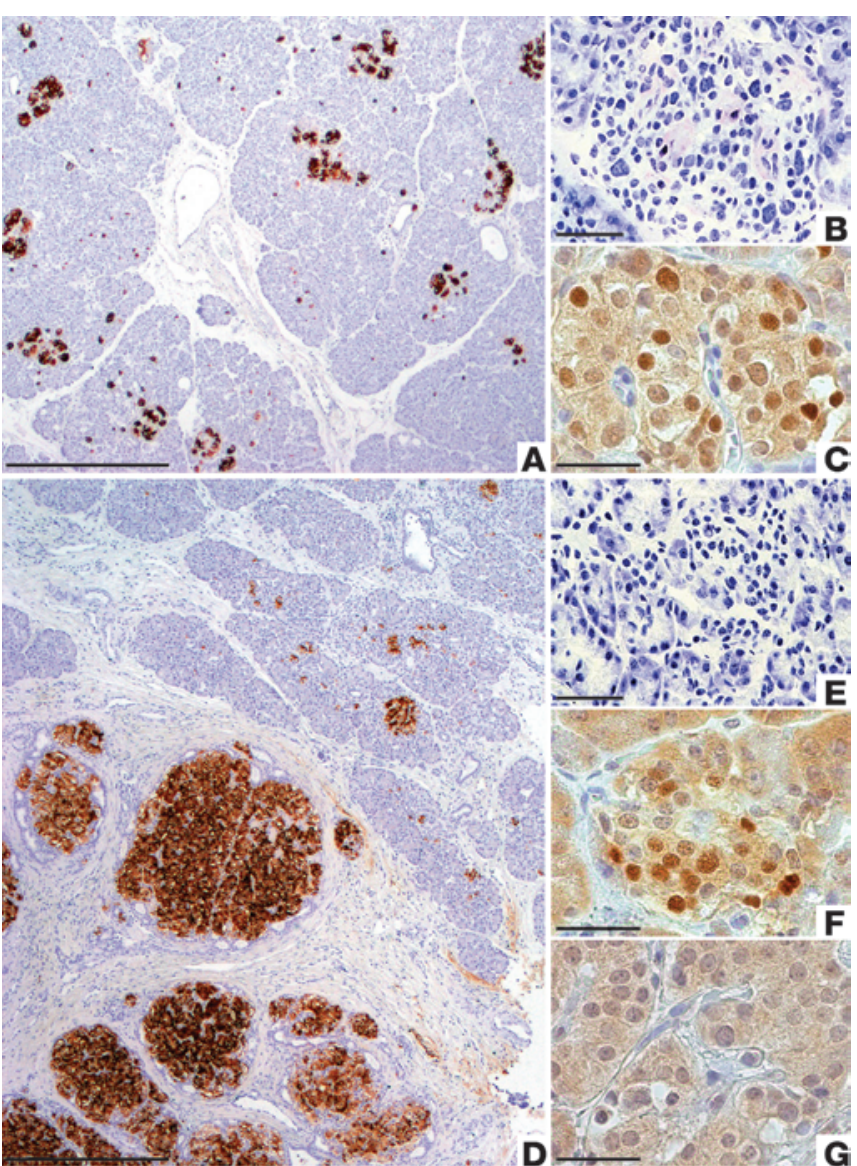

of glucose was $\mathrm{Ca}^{2+}$ dependent, but it is not known whether it was sensitive to diazoxide (21). Unfortunately, in none of the above studies was appropriate control tissue available for comparison.

In the present study, we used a perifusion system to characterize in vitro the kinetics of insulin secretion by the pancreas of 24 infants suffering from diazoxide-resistant FoCHI or DiCHI because of inactivating mutations of $\mathrm{K}_{\mathrm{ATP}}$ channels in their $\beta$ cells. In all cases, intraoperative microscopic examination of frozen sections established the differential diagnosis (19) and dictated the localization and extent of pancreatic resection. This also made it possible to select fragments of normal and pathologic tissue from the pancreas of patients with FoCHI and to compare their secretory behavior. Such a comparison is crucial for identification and correct interpretation of abnormalities in the focal lesion and in the whole pancreas from DiCHI patients.

\section{Results}

Morphological aspect of DiCHI and FoCHI pancreas. The 6 DiCHI and 18 FoCHI studied subjects (Table 1) underwent pancreatic surgery because of their clinical resistance to diazoxide treatment. In DiCHI pancreas, the number, size, and general appearance of the islets (Figure 1A) are similar to those in

\section{Figure 1}

$\mathrm{DiCHI}$ and FoCHI pancreas: morphological aspect and CDKN1C expression in islets. The pancreas of representative cases of $\mathrm{DiCHI}$ (A) and $\mathrm{FoCHI}$ (D) patients were postoperatively immunostained for insulin. DiCHI does not show obvious changes in islet number or size, whereas $\mathrm{FoCHI}$ is characterized by a localized adenomatous hyperplasia of $\beta$ cells. Peroperative diagnosis of $\mathrm{DiCHI}$ on frozen sections is based on the presence of $\beta$ cells with a large nucleus and abundant clear cytoplasm (B, toluidine staining). In FoCHI, islets outside the lesion are small and contain $\beta$ cells with a relatively small nucleus and scanty cytoplasm (E). CDKN1C (p57) peptide is present in several cells of all $\mathrm{DiCH}$ islets (C, dark brown nuclei) and islets located outside the lesion in $\mathrm{FoCHI}(\mathbf{F})$, but it is absent from the focal lesion (G). Scale bars: $500 \mu \mathrm{m}$ (A and D); $25 \mu \mathrm{m}$ (B, C, E-G).

the pancreas from control infants (11). Intraoperative diagnosis, based on the presence of $\beta$ cells with an abnormally large nucleus and abundant cytoplasm in frozen specimens (Figure 1B), was subsequently confirmed on fixed specimens. The pattern is different in FoCHI pancreas. As shown in Figure 1D, focal lesions consist of an agglomerate of large islets. The size of the lesion is variable (usually $<10 \mathrm{~mm}$ in diameter), and its limits are not always as regular as in the figure. Outside the focal lesion, islets contain $\beta$ cells with a small nucleus and relatively little cytoplasm, which give the impression of packed cells (Figure 1E and ref. 11). In DiCHI, CDKN1C is normally expressed, so that all islets contain cells positive for the CDKN1C ( $\mathrm{p} 57$ ) protein (Figure 1C). In FoCHI pancreas, CDKN1C immunostaining is positive in islets outside the lesion (Figure 1F) but negative in the focal lesion (Figure 1G) because of the loss of maternal 11p15 $(16,17)$. These characteristics were present in all studied cases.

When intraoperative diagnosis of DiCHI was established, subtotal pancreatectomy was performed and an unselected fragment of the whole organ was saved for functional studies. In FoCHI, the resection was limited to the lesion and a zone of normal tissue at the periphery. The pieces of pathological and normal tissue destined for functional studies were selected by morphological examination of adjacent frozen samples, with a preference for the inconvenience of small size over the risk of overlapping zones.

Insulin content and insulin secretion during culture. The initial insulin content of fresh pancreas was not directly measured but estimated by adding the total amount of insulin secreted during the experiments

\section{Table 2}

Insulin secretion during tissue culture and estimation of initial insulin concentration in the normal and pathological pancreas

\begin{tabular}{lcc}
\hline & $\begin{array}{c}\text { Initial insulin content } \\
(\mathbf{n g} / \mathbf{m g})\end{array}$ & $\begin{array}{c}\text { Insulin secretion during culture } \\
(\% \text { of content in } \sim 19 \text { hours })\end{array}$ \\
$\begin{array}{l}\text { FoCHI pancreas }(\boldsymbol{n = 1 7 )} \\
\text { Normal region }\end{array}$ & $46.2 \pm 6.6(16-113)$ & $21.5 \pm 7.2(9-38)$ \\
Lesion & $515 \pm 60(204-1048)$ & $29.5 \pm 8.4(15-40)$ \\
Ratio: lesion/normal & $14.0 \pm 2.5(5.2-37.4)$ & $1.40 \pm 0.14(0.7-2.6)$ \\
DiCHI pancreas $(\boldsymbol{n}=\mathbf{6})$ & & \\
Whole pancreas & $38.6 \pm 19.3(11-64)$ & $24.7 \pm 11.5(13-40)$ \\
Ratio: diffuse/normal focal & 0.84 & 1.15
\end{tabular}

Insulin secretion was measured during the culture period (17-22 hours) preceding transfer of the tissue into perifusion chambers. It is expressed as a percentage of the initial insulin content of the tissue, which was calculated as described in Methods. Values are mean \pm SEM with range in parentheses. Data are missing for $1 \mathrm{FoCHI}$ pancreas. 
A

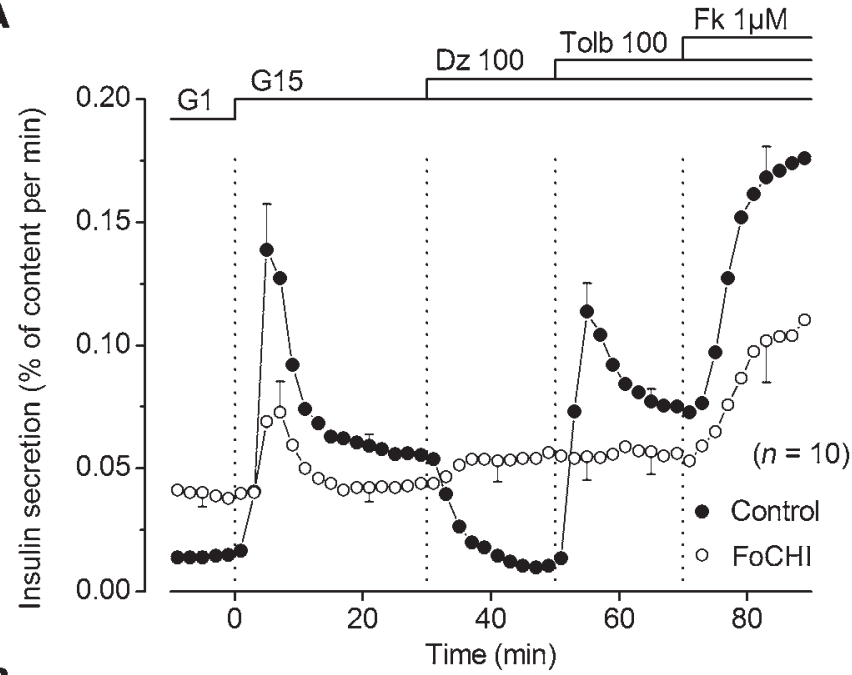

B

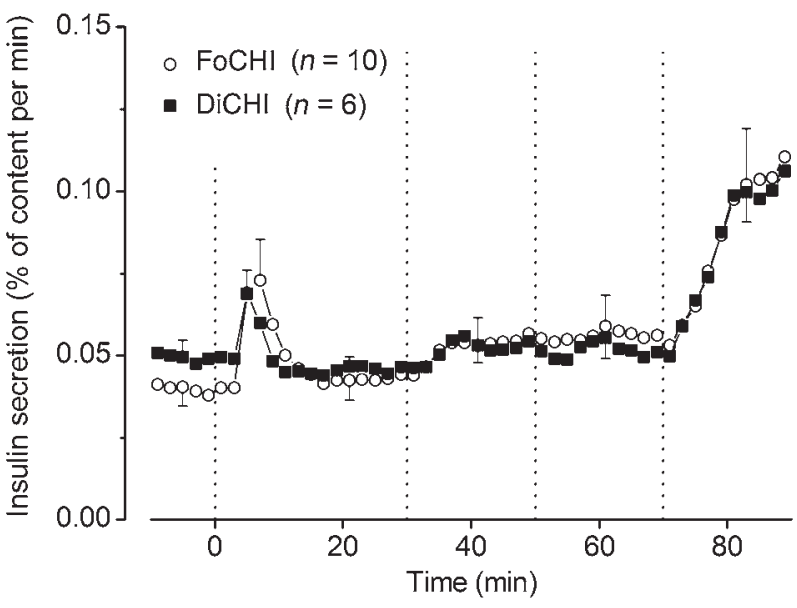

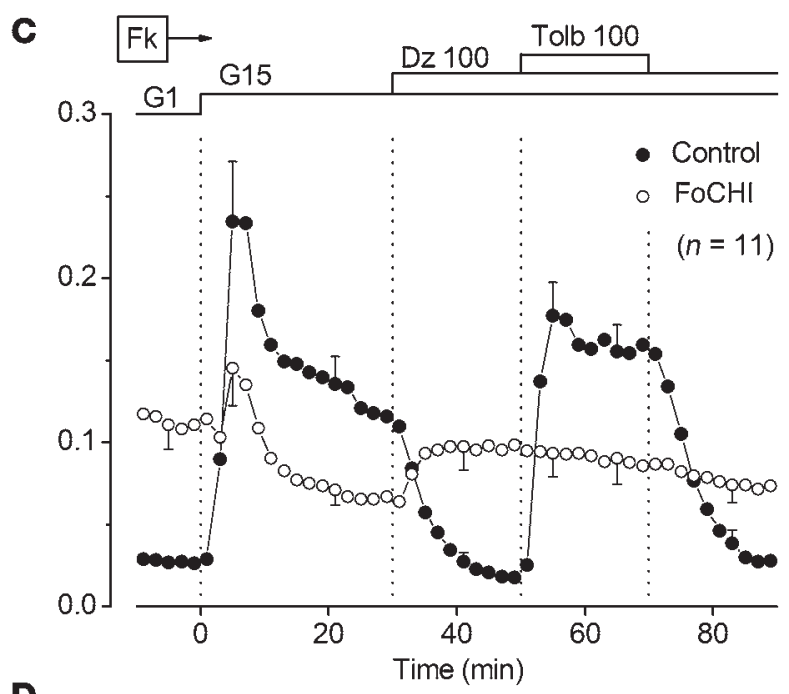

。

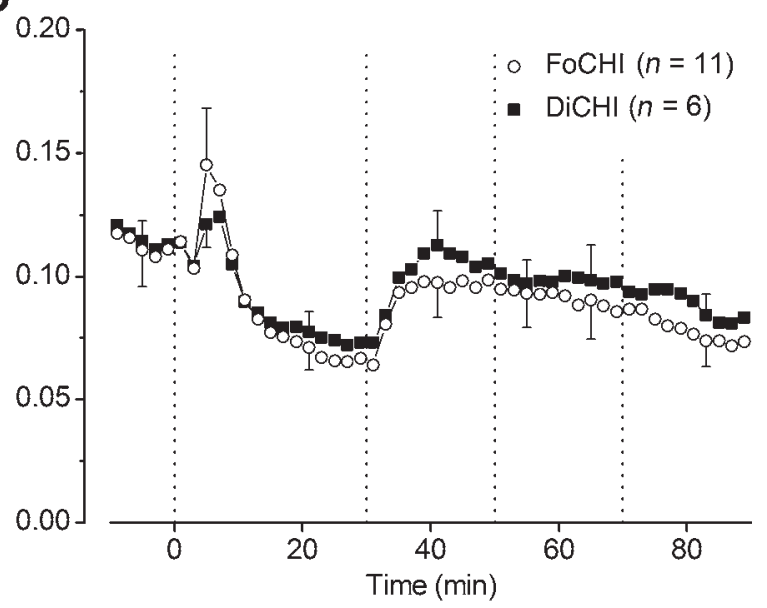

Figure 2

Effects of glucose and drugs acting on $\mathrm{K}_{\text {ATP }}$ channels on insulin secretion by control, FoCHI, and DiCHI pancreas. (A and C) Comparison of insulin secretion from the focal lesion and the adjacent normal pancreas of the same subjects. (B and $\mathbf{D})$ Comparison of insulin secretion from focal lesions and the pancreas of $\mathrm{DiCHI}$ subjects; results obtained in focal lesions are the same as those presented in the above panels, but are shown with another scale. The concentration of glucose $(\mathrm{G})$ was increased from 1 to $15 \mathrm{mM}$, and $100 \mu \mathrm{M}$ diazoxide (Dz) and $100 \mu \mathrm{M}$ tolbutamide (Tolb) were added as indicated at the top of the figures. In A and B, $1 \mu \mathrm{M}$ forskolin (Fk) was added at 70 minutes. In $\mathbf{C}$ and $\mathbf{D}, 1 \mu \mathrm{M}$ forskolin was present throughout. Values are mean \pm SEM for the indicated number of subjects. Individual responses are shown in Supplemental Figures 1-4.

and the tissue content at the end of the experiments (see Methods). The normal region of FoCHI pancreas contained $46 \mathrm{ng}$ insu$\mathrm{lin} / \mathrm{mg}$ on average and secreted $21.5 \%$ of this content during the approximately 19 hours of culture in the presence of $5 \mathrm{mM}$ glucose (Table 2). In the focal lesion, the insulin content was 14-fold greater than in the normal region, but fractional insulin secretion during culture $(29.5 \%)$ was not consistently larger (on average 1.4-fold, NS by paired $t$ test). In DiCHI pancreas, insulin content $(39 \mathrm{ng} / \mathrm{mg}$ ) and fractional insulin secretion during culture $(24.7 \%)$ were not different from those in the normal region of FoCHI pancreas (Table 2). The surprising similarity between fractional insulin secretion rates in FoCHI and DiCHI tissue and in normal pancreas is attributed to the stimulation of normal islets by the concentration of $5 \mathrm{mM}$ glucose in culture medium (see below).

Acute effects of glucose on insulin secretion. Stimulation of the normal pancreas of FoCHI subjects by a rapid increase in glucose from 1 to $15 \mathrm{mM}$ induced biphasic insulin secretion (Figure 2A).
Second phase was suppressed by diazoxide and restored by tolbutamide. At the end of the experiments, addition of forskolin to increase cAMP in $\beta$ cells doubled insulin secretion (Figure $2 \mathrm{~A})$. The presence of forskolin during the whole experiment augmented the amplitude of both first and second phases of glucose-induced secretion, but did not alter the inhibitory and stimulatory effects of diazoxide and tolbutamide (compare Figure $2 \mathrm{C}$ with Figure $2 \mathrm{~A}$ and note the different scales). These changes, here measured with partially digested pancreas, are superimposable on those observed with isolated islets from adult organ donors (26). At least one of the protocols shown in Figure 2, A and C, was performed with normal pancreas of each FoCHI patient and gave qualitatively similar results, attesting to the quality of the tested tissues. Supplemental Figures 1 and 2 (supplemental material available online with this article; doi:10.1172/JCI58400DS1) show all individual responses in the absence and presence of forskolin, respectively. 
A

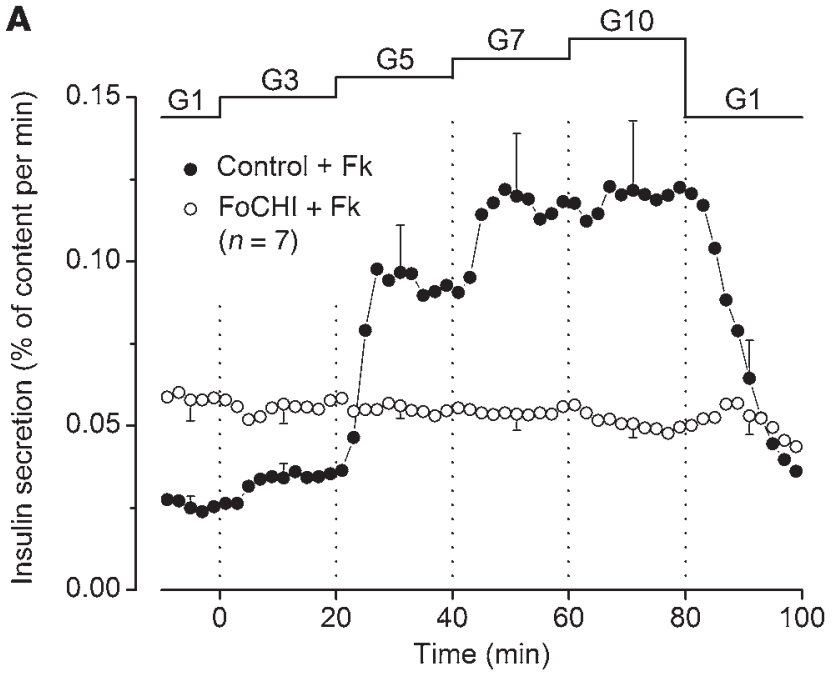

B

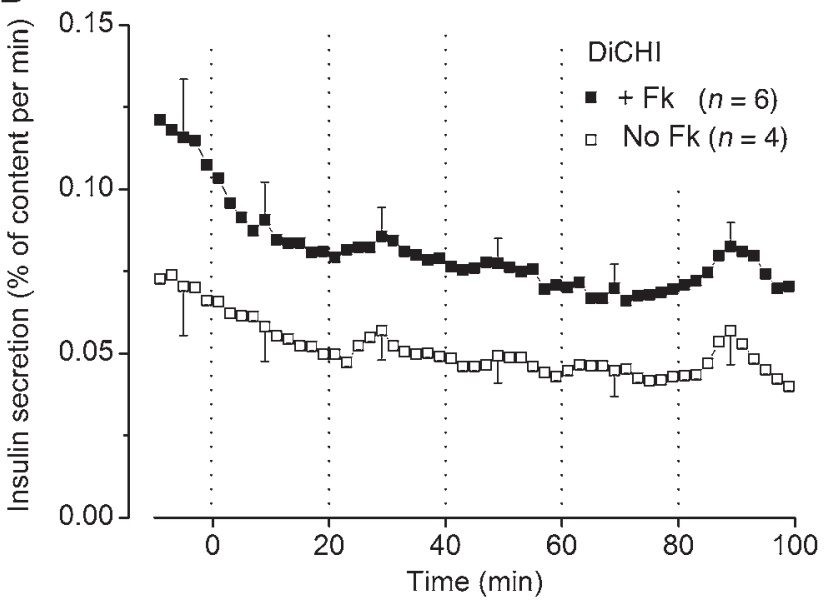

C

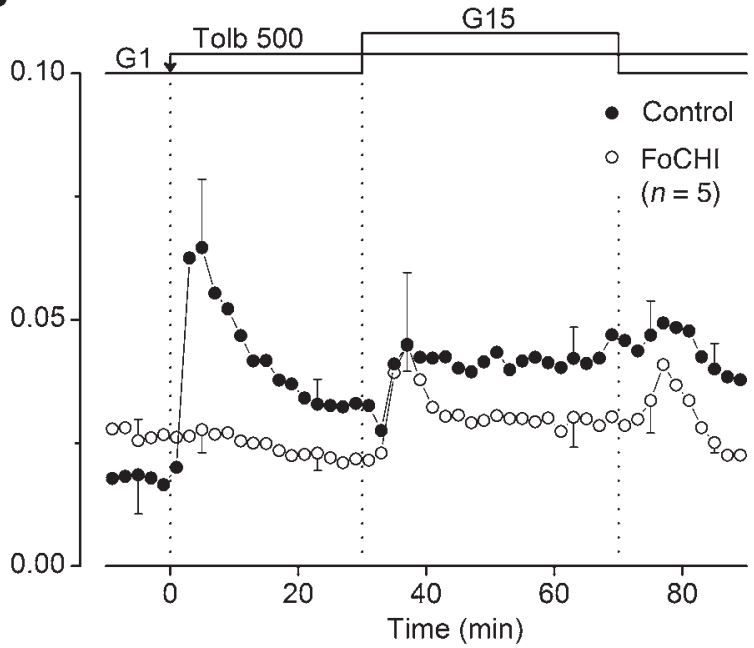

D

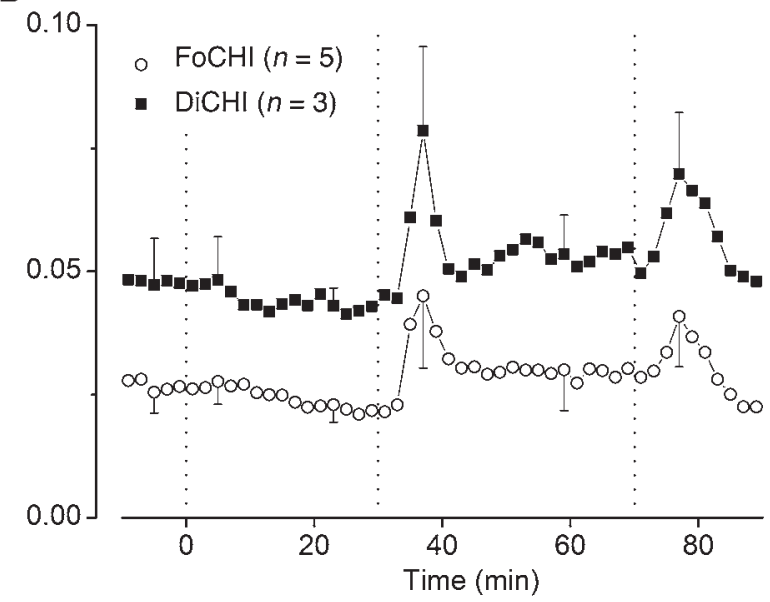

Figure 3

Effects of glucose and tolbutamide on insulin secretion by control, FoCHI, and DiCHI pancreas. (A and B) Effects of stepwise increases in glucose (in $\mathrm{mM}$ ). (A) Responses of focal lesion and adjacent normal pancreas of the same subjects. The experiments were performed in the presence of $1 \mu \mathrm{M}$ forskolin throughout. (B) Responses of DiCHI pancreas in the presence and absence of forskolin. (C and D) Effects of high glucose in the presence of tolbutamide. (C) Responses of focal lesion and adjacent normal pancreas of the same subjects. (D) Responses of the same focal lesions and of $\mathrm{DiCH}$ pancreas. Tolbutamide $(500 \mu \mathrm{M})$ was added, and the concentration of glucose was increased from 1 to $15 \mathrm{mM}$ as indicated. The experiments were performed in the absence of forskolin. Values are mean \pm SEM for the indicated number of subjects.

The focal lesion of the same subjects was characterized by an elevated basal insulin secretion rate in $1 \mathrm{mM}$ glucose $(2.8$-fold higher than in paired control pancreas; $P<0.001$ ) (Figure 2A). Stimulation by $15 \mathrm{mM}$ glucose induced a modest first phase of insulin secretion in 6 of 10 focal lesions $(P<0.01$ for all responses), and a small second phase increase above the high prestimulatory values was detected in only 3 of 10 subjects. Diazoxide never inhibited insulin secretion but unexpectedly increased it in 3 of 10 subjects (Supplemental Figure 1), although the mean change was not significant (Figure 2A). Tolbutamide was always ineffective, and forskolin, added at the end of the experiments, approximately doubled the secretion rate (Figure $2 \mathrm{~A}$ ).

When forskolin was present from the start of the experiments, basal insulin secretion was augmented and the difference with paired control pancreas now averaged 4.1 -fold $(P<0.001)$ (Figure 2 C). Stimulation with $15 \mathrm{mM}$ glucose induced a small first peak of secretion in 5 of 11 preparations ( $P<0.05$ for all responses). This small peak was followed by a paradoxical decrease $(P<0.01)$ during second phase. We acknowledge that, in the absence of paired experiments in low glucose throughout, it is debatable whether the average decrease in insulin secretion rate (Figure 2C) was induced by high glucose or was spontaneous. However, examination of the individual responses (Supplemental Figure 2) suggests that an inhibition by glucose was real in 6 of 11 cases. Equally paradoxical was the increase in insulin secretion produced by diazoxide in 6 of 11 cases (Supplemental Figure 2$)(P<0.05$ for all responses). In contrast, tolbutamide was always without effect (Figure 2B). In 3 other experiments, omission of $\mathrm{CaCl}_{2}$ from the perifusion medium markedly inhibited the high rate of insulin secretion in FoCHI pancreas (not shown).

Mean insulin secretory responses of DiCHI pancreas were similar to those of focal lesions (Figure 2, B and D). Responses of individual DiCHI cases tested without and with forskolin are shown in Supplemental Figures 3 and 4. In the presence of forskolin throughout, $15 \mathrm{mM}$ glucose induced an initial peak of insulin secretion in 4 of 

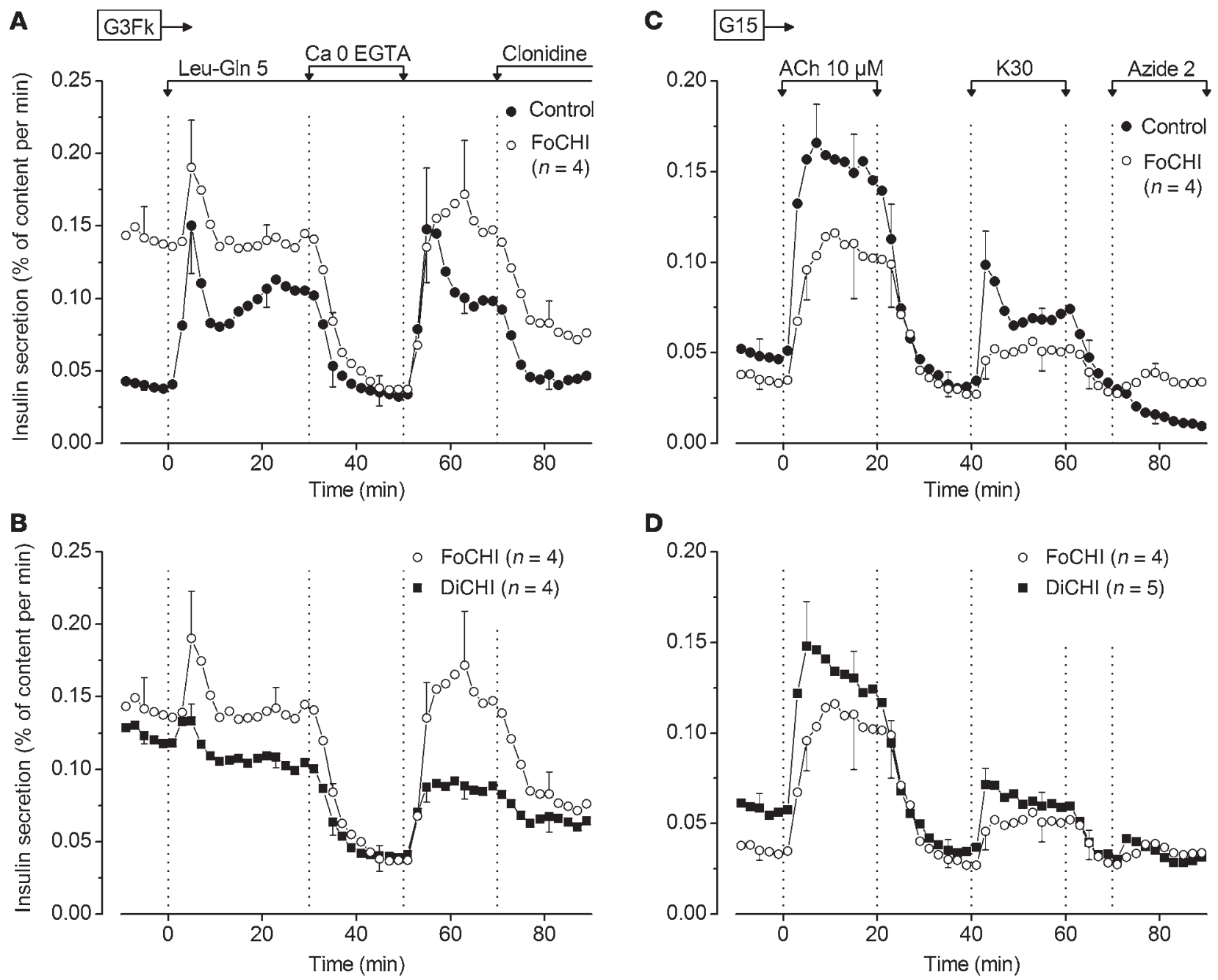

\section{Figure 4}

Effects of various stimulators and inhibitors on insulin secretion by control, $\mathrm{FoCHI}$, and DiCHI pancreas. (A and $\mathbf{B})$ Effects of amino acids, $\mathrm{CaCl} 2$ omission, and clonidine. (A) Responses of focal lesion and adjacent normal pancreas of the same subjects. (B) Responses of the same focal lesions and of $\mathrm{DiCHI}$ pancreas. The experiments were performed in the presence of $3 \mathrm{mM}$ glucose and $1 \mu \mathrm{M}$ forskolin throughout (G3 Fk). Leucine and glutamine $\left(5 \mathrm{mM}\right.$ each) and clonidine $(1 \mu \mathrm{M})$ were added, and extracellular $\mathrm{CaCl}_{2}$ was omitted (with addition of $100 \mu \mathrm{M}$ EGTA) as indicated. (C and D) Effects of acetylcholine, $\mathrm{KCl}$, and azide. (C) Responses of focal lesion and adjacent normal pancreas of the same subjects. (D) Responses of the same focal lesions and of DiCHI pancreas. The experiments were performed in the presence of $15 \mathrm{mM} \mathrm{glucose}(\mathrm{G} 15)$ and absence of forskolin throughout. Acetylcholine $(10 \mu \mathrm{M})$ and azide $(2 \mathrm{mM})$ were added, and the concentration of $\mathrm{KCl}$ was raised to $30 \mathrm{mM}(\mathrm{K} 30)$ as indicated. Values are mean \pm SEM for the indicated number of subjects.

6 subjects and a paradoxical decrease below initial values during second phase in 5 of 6 subjects $(P<0.01)$. The stimulatory effect of diazoxide was consistently observed $(6$ of 6$)(P<0.01)$. Pinacidil, a structurally unrelated $K_{\text {ATP }}$ channel opener with greater affinity for SUR2 than SUR1, inhibits glucose-induced insulin secretion in normal islets (27) and, like diazoxide, is inactive in Sur1-knockout islets (28). Pinacidil also paradoxically increased insulin secretion in FoCHI lesion and DiCHI pancreas perifused with $3 \mathrm{mM}$ glucose $(P=0.01)$, while having no effect in normal pancreas (Supplemental Figure 5).

Stepwise increases of the glucose concentration in the presence of forskolin induced a concentration-dependent increase in insulin secretion in the normal pancreas from FoCHI subjects (Figure 3A). A response was already evoked by $3 \mathrm{mM}$ glucose in 4 of 7 cases $(P<0.01$ for the whole group), and a maximum was reached at $7 \mathrm{mM}$ glucose.
Excellent reversibility was observed on return to $1 \mathrm{mM}$ glucose at the end of the experiments. Whereas the threshold at $3 \mathrm{mM}$ was the same as in adult islets, the maximum effect of glucose was reached at a lower concentration (26). These progressive changes in glucose concentration were without significant effect on insulin secretion by focal lesions in the presence of forskolin (Figure 3A). They were also ineffective in DiCHI pancreas, both in the presence and absence of forskolin (Figure 3B).

In the presence of only $1 \mathrm{mM}$ glucose, tolbutamide, used at the concentration of $500 \mu \mathrm{M}$ to close all $\mathrm{K}_{\mathrm{ATP}}$ channels, consistently stimulated insulin secretion from normal pancreas of FoCHI patients (Figure 3C). An initial peak was followed by a slow decline and stabilization at approximately 1.8 -fold above baseline $(P<0.05)$. Subsequently, raising the concentration of glucose to $15 \mathrm{mM}$ in the 

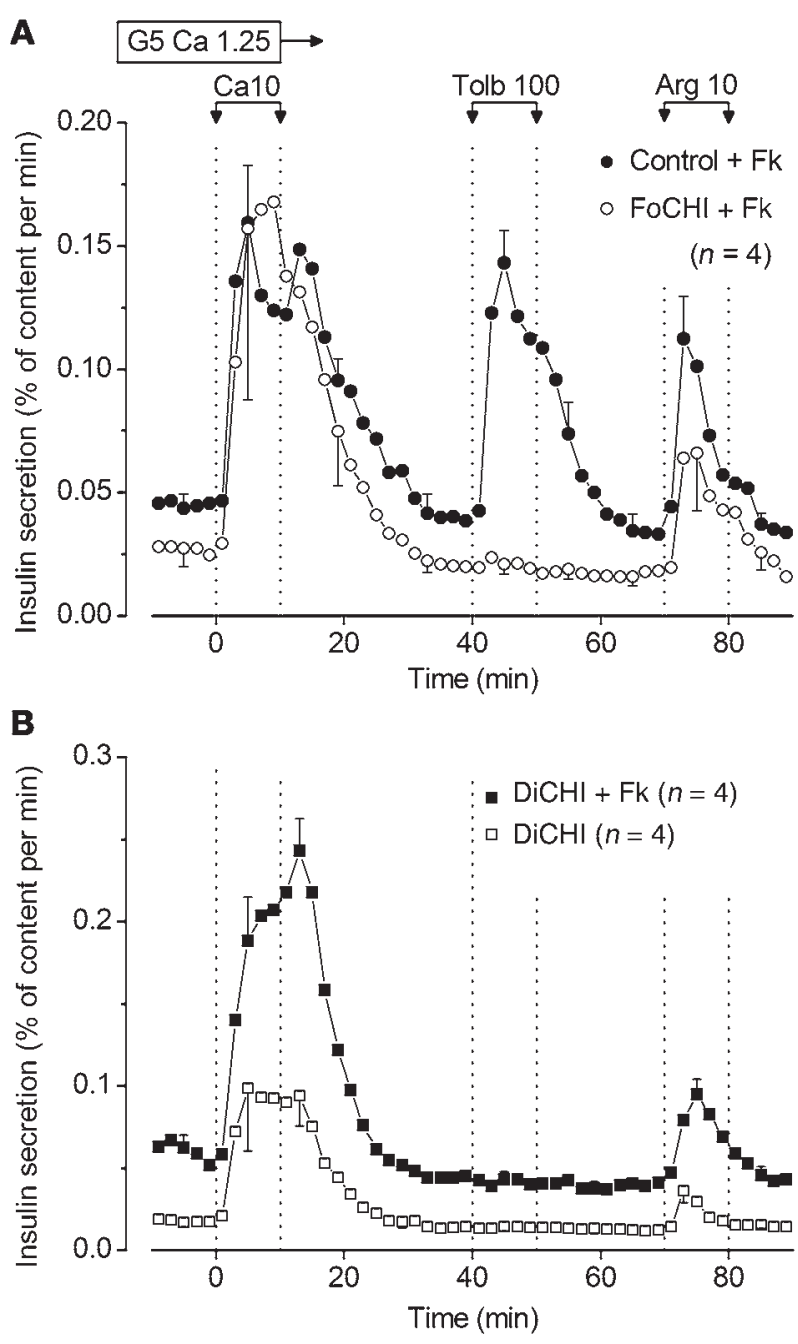

presence of tolbutamide was followed by a slight increase in insulin secretion (4 of 5 subjects) $(P<0.05)$, an effect that is attributed to the amplifying pathway (8). In focal lesion, tolbutamide was ineffective in $1 \mathrm{mM}$ glucose, but the subsequent increase in glucose induced a first peak of insulin secretion ( 4 of 5 subjects) $(P<0.05)$ and a minor and inconsistent ( 2 of 5 ) sustained elevation (NS for the whole group). A qualitatively similar response was observed in DiCHI pancreas (Figure 3D). In focal lesion and DiCHI pancreas, these effects of glucose on top of tolbutamide are not different from those of glucose alone (compare with Figure 2B).

Acute effects of other agents on insulin secretion. In the presence of 3 $\mathrm{mM}$ glucose and forskolin throughout, the combination of leucine and glutamine (5 $\mathrm{mM}$ each) induced biphasic insulin secretion from the normal pancreas of FoCHI patients (Figure 4A). The effect of the amino acids was reversibly abrogated by omission of extracellular $\mathrm{CaCl}_{2}$ and markedly inhibited by activation of $\alpha_{2}$-adrenoceptors with clonidine. In focal lesion, the combination of amino acids evoked a first-phase insulin secretion in 4 of 4 preparations $(P=0.05)$ but no secondary elevation. $\mathrm{CaCl}_{2}$ omission inhibited the high rate of secretion to basal values similar to those in control pancreas, i.e., well below the initial secretion rate in focal lesions. Clonidine caused partial inhibition (Figure 4A). In DiCHI pancreas, leucine and glutamine induced a first-phase insulin

\section{Figure 5}

Effects of $\mathrm{CaCl}_{2}$, tolbutamide, and arginine on insulin secretion by control, FoCHI, and DiCHI pancreas. (A) Responses of focal lesion and adjacent normal pancreas of the same subjects. (B) Responses of $\mathrm{DiCHI}$ pancreas. The experiments were performed in the presence of $5 \mathrm{mM}$ glucose (G5) throughout. The concentration of $\mathrm{CaCl}_{2}$ was $1.25 \mathrm{mM}$ except during 10 minutes when it was increased to $10 \mathrm{mM}$ (Ca10). Tolbutamide (100 $\mu \mathrm{M})$ and $10 \mathrm{mM}$ arginine (Arg) were added as indicated. Forskolin $(1 \mu \mathrm{M})$ was present in all experiments in $\mathbf{A}$ and in 1 series only in $\mathbf{B}$. Values are mean \pm SEM for the indicated number of subjects.

secretion in only 2 of 4 preparations. Omission of $\mathrm{CaCl}_{2}$ consistently suppressed secretion, while clonidine was inhibitory in 3 of 4 preparations (Figure 4B), as was epinephrine in a previous study (25). In mouse islets lacking $\mathrm{K}_{\mathrm{ATP}}$ channels because of a knockout of Sur1, clonidine abrogated insulin secretion by lowering $\left[\mathrm{Ca}^{2+}\right]_{c}$ and interfering with exocytosis (28). In a single case (DiCHI1), glutamine $(2 \mathrm{mM})$ was tested alone and only had a very small effect on insulin secretion, in contrast with the large response induced by a mixture of amino acids (Supplemental Figure 6).

In the presence of $15 \mathrm{mM}$ glucose, acetylcholine and $\mathrm{KCl}$ reversibly increased insulin secretion in the normal pancreas of FoCHI patients (Figure 4C). At the end of the experiments, addition of azide, a mitochondrial poison that lowers ATP levels in islets (29), abolished insulin secretion. In focal lesions, qualitatively similar but slightly smaller effects were produced by acetylcholine (4 of 4) and $\mathrm{KCl}$ (3 of 4). In contrast, azide did not inhibit insulin secretion (Figure $4 \mathrm{C}$ ). The responses of DiCHI pancreas were similar to those of FoCHI pancreas (Figure 4D). We tentatively attribute the smaller effects of $\mathrm{KCl}$ and acetylcholine to a lesser stimulation of $\mathrm{Ca}^{2+}$ influx in depolarized CHI $\beta$ cells. The suppression of glucose-induced insulin secretion by azide in control pancreas is attributed to the opening of $\mathrm{K}_{\mathrm{ATP}}$ channels with subsequent lowering of $\left[\mathrm{Ca}^{2+}\right]_{\mathrm{c}}$. No such effect can occur in CHI $\beta$ cells lacking functional $\mathrm{K}_{\text {ATP }}$ channels (29).

Acute effects of diagnostic agents on insulin secretion. Acute stimulation by $\mathrm{CaCl}_{2}$, tolbutamide, or arginine are commonly used tests in the diagnostic phase of $\mathrm{CHI}(30-33)$. In the presence of $5 \mathrm{mM}$ glucose and forskolin, an increase in extracellular $\mathrm{CaCl}_{2}$ from 1.25 to $10 \mathrm{mM}$ evoked a large peak of insulin secretion in the normal pancreas of FoCHI patients, and so did $100 \mu \mathrm{M}$ tolbutamide and $10 \mathrm{mM}$ arginine (Figure 5A). In focal lesions, $\mathrm{CaCl}_{2}$ and arginine also induced peaks of insulin secretion, whereas tolbutamide had no effect. In DiCHI pancreas, tolbutamide was consistently ineffective in contrast with $\mathrm{CaCl}_{2}$ and arginine, the effects of which were markedly potentiated by forskolin (Figure 5B).

\section{Discussion}

Preparation. Because islet organization is altered in focal adenomatous lesions, we dispersed normal and pathological fragments in exactly the same way. Although morphological (Figure 1 and ref. 11) and functional (32) indices suggest that $\beta$ cells are quiescent outside focal lesions, secretory responses by fragments of normal pancreas from FoCHI patients were similar to those by islets isolated from healthy adult organ donors (26). This means that any alterations of $\beta$ cell function in vivo (e.g., by drug treatment or lack of stimulation) have been reversed by the initial 17-22 hours of culture in $5 \mathrm{mM}$ glucose. However, 2 quantitative differences must be pointed out. First, whereas the low threshold of $3 \mathrm{mM}$ for glucose-induced insulin secretion is similar in islets and fragments, 
the maximum effect of glucose is reached at a much lower concentration (7 vs. $15 \mathrm{mM}$ ) in fragments of infant pancreas. Second, the increase in insulin secretion occurring when the concentration of glucose is raised after closure of $\mathrm{K}_{\mathrm{ATP}}$ channels by tolbutamide (measure of the amplifying pathway) is of smaller magnitude than in adult islets (26). Because no similar studies with islets from normal young infants are available, it is unclear whether these differences are solely attributable to the age of the subjects. With this reservation, we are confident that our procedure did not distort $\beta$ cell secretory function. Most importantly, results obtained with focal lesions were included in the study only when healthy pancreas from the same patient was available for comparison and displayed qualitatively normal responses to glucose, diazoxide, and tolbutamide (Supplemental Figures 1 and 2). This control is crucial to ascertain that abnormal responses of the lesion are not simply due to tissue damage. Normal pancreas from FoCHI patients was also used as control for the responses recorded in DiCHI that affects all islets from the patients.

Major abnormalities of insulin secretion in CHI pancreas. We first acknowledge that, in contrast to the good intersubject reproducibility of insulin secretion in normal pancreas, some alterations were inconsistently observed in focal lesion and DiCHI pancreas, which complicates their interpretation. We next emphasize that our study was performed in a subgroup of $\mathrm{CHI}$ infants requiring partial or subtotal pancreatectomy because of clinical resistance to diazoxide and other medical treatment. The abnormalities of insulin secretion would be different if the mutations led to expression of partially functional $\mathrm{K}_{\mathrm{ATP}}$ channels or to defects in other pathways. In both focal lesion and DiCHI pancreas, insulin secretion rate in the presence of 1-3 mM glucose (with or without forskolin) was consistently elevated compared with that in normal pancreas. This is attributable to continuous depolarization of $\beta$ cells (5) due to the lack of $\mathrm{K}_{\mathrm{ATP}}$ channels and elevation of $\left[\mathrm{Ca}^{2+}\right]_{\mathrm{c}}$ even in low glucose concentrations (20). Thus, as previously reported (25), omission of extracellular $\mathrm{CaCl}_{2}$ lowered insulin secretion by $\mathrm{CHI}$ pancreas to basal rates similar to those in normal pancreas.

The differences in insulin secretion rates between $\mathrm{CHI}$ and normal pancreas disappeared or were reversed at $5 \mathrm{mM}$ glucose and above because the stimulatory action of glucose occurred in normal tissue only. The effects of glucose were indeed peculiar in $\mathrm{CHI}$ pancreas. Small stepwise increases in its concentration had no effect, while a larger step ( 1 to $15 \mathrm{mM}$ ) sometimes produced a rapid but small increase in insulin secretion above the already elevated initial level. Most often, the increase was transient and followed by a decrease of insulin secretion (particularly in the presence of forskolin) rather than by a sustained second phase elevation. A rapid and transient secretion of insulin also occurred in response to leucine plus glutamine, but this was not followed by a secondary decrease. In the absence of precise information on how $\left[\mathrm{Ca}^{2+}\right]_{c}$ changes under these conditions, no mechanistic explanation is straightforward. In one single study of islets from 3 DiCHI patients (21), high glucose concentrations did not increase the surprisingly low basal $\left[\mathrm{Ca}^{2+}\right]_{c}$. Cautious extrapolation to the present study would therefore suggest that the peak of insulin secretion produced by glucose is due to the amplifying pathway. Although recent work established that metabolic amplification is of rapid onset and contributes to both phases of glucose-induced insulin secretion in normal mouse islets $(8,34)$, it remains unclear why it was not sustained to produce a second phase increase in $\mathrm{CHI}$ pancreas (further discussion in next paragraph).
Whereas the consistent ineffectiveness of tolbutamide in $\mathrm{CHI}$ pancreas conforms to model predictions, the increase in insulin secretion that diazoxide produced in several cases is paradoxical and not predicted by any model. It is unlikely to reflect an indirect action via neighboring non- $\beta$ cells, such as inhibition of somatostatin release (35), because the germinal mutation (DiCHI patients) also affects $K_{\text {ATP }}$ channels in $\delta$ cells. Higher concentrations of diazoxide have been reported to affect mitochondrial membrane potential and slightly decrease ATP production (36), but such an effect is not expected to increase insulin secretion. Since pinacidil, another opener of $\mathrm{K}_{\mathrm{ATP}}$ channels in normal $\beta$ cells (27), reversibly increased insulin secretion in both focal lesion and DiCHI pancreas, a mere artefact of diazoxide is unlikely, but the cellular target remains unknown.

Comparisons with animal models. Unlike infants with diazoxideresistant CHI, mice with a knockout of either Sur1 or Kir6.2, thus lacking $\mathrm{K}_{\mathrm{ATP}}$ channels in their $\beta$ cells, spontaneously correct their postnatal hypoglycemia within a few days $(37,38)$, and only fasting can disclose mild hypoglycemia in adults (39-41). In vitro, their islets show $\mathrm{Ca}^{2+}$-dependent elevation of insulin secretion in low glucose concentrations and complete insensitivity to tolbutamide and diazoxide $(28,37-39,42-44)$. Notably, the paradoxical increase in insulin secretion produced by diazoxide in $\mathrm{CHI}$ pancreas has never been reported in mice. There is general agreement that glucose only weakly increases insulin secretion in the perfused pancreas or freshly isolated islets from these models (37-39, 42-45) except when the cAMP pathway $(44,46)$ or the protein kinase $C$ pathway $(44,47)$ is activated. In CHI pancreas, cAMP (forskolin) augmented insulin secretion but did not induce glucose responsiveness. Similar observations have been made with long-term cultures of DiCHI pancreas challenged with phosphodiesterase inhibitors (24, 25). Acetylcholine similarly increased insulin secretion in $\mathrm{CHI}$ and normal pancreas in $15 \mathrm{mM}$ glucose, but the experiments were not appropriate to detect whether CHI $\beta$ cells are hyperresponsive to the neurotransmitter as are Sur1-knockout islets $(44,47)$.

We $(43,48)$ and others $(49,50)$ observed that overnight culture of Sur1- or Kir6.2-knockout islets influenced basal secretion rates in low glucose concentrations and unmasked strong sustained effects of glucose on insulin secretion, which could be attributed to a very efficient amplifying pathway and, more unexpectedly, to a $\mathrm{K}_{\mathrm{ATP}}$ channel-independent control of $\mathrm{Ca}^{2+}$ influx (42, $43,45)$. Although our fragments of CHI pancreas were studied after overnight culture in $5 \mathrm{mM}$ glucose, no sustained stimulation of insulin secretion was observed. These discrepancies cannot be attributed to age because islets from 2-week-old Sur1- or Kir6.2-knockout mice behaved like islets from adult mice $(43,45)$. It seems that a lack of $\mathrm{K}_{\mathrm{ATP}}$ channels does not lead to the same adaptation mechanisms in mouse and human $\beta$ cells.

As already alluded to above, the poor efficacy of the amplifying pathway in CHI pancreas is intriguing. This may be one key to the phenotypic differences between the 2 species. In islets from one Sur1-knockout model (39), glutamine potently increased insulin secretion in the presence of low glucose, an effect that was barely augmented by leucine, used to activate glutamate dehydrogenase $(40,51)$. These and other observations in normal islets prompted the suggestion that glutamine serves as coupling factor in metabolic amplification of exocytotic responses to $\mathrm{Ca}^{2+}(51,52)$. It was also proposed that inhibition of the GABA shunt in Sur1-knockout $\beta$ cells contributes to their hyposensitivity to glucose and hypersensitivity to amino acids (52). We cannot exclude that simi- 
lar alterations underlie the poor responsiveness of CHI pancreas to glucose but wish to remain very cautious in such extrapolations between species. Thus, in our own studies using islets from the other Sur1-knockout model (38), glutamine alone had virtually no effect on insulin secretion in contrast with activation of glutamate dehydrogenase (42). We also point out that glutamine alone was poorly effective in the pancreas of a single DiCHI subject (Supplemental Figure 6). Finally, it is puzzling that the amplifying pathway is less efficient in normal pancreas from FoCHI patients than in normal adult islets. The question thus remains open.

Comparison between insulin secretion in vitro and in vivo. Insulin secretion has been studied in CHI infants before surgery, generally in an attempt to distinguish between FoCHI and DiCHI. The tolbutamide stimulation test only poorly distinguishes between the 2 forms for 2 reasons. First, some mutations do not completely suppress $\beta$ cell sensitivity to sulfonylureas, and second, the normal pancreas in FoCHI does not always strongly respond to tolbutamide, perhaps because of a long-lasting resting state induced by ambient low glucose or drug treatment $(32,33,53)$. This was not the case in our in vitro studies of FoCHI pancreas, in which tolbutamide was consistently inactive in focal lesion and active in normal tissue, possibly relieved from any inhibition by the overnight culture period. In cases of null mutations in ABCC 8 or KCNJ11, the test could still be helpful if performed after elevation of blood glucose levels to prime the normal pancreas.

In many patients with either form of CHI, an acute increase in plasma insulin levels was observed after i.v. glucose injection (32, $33,53)$. While this increase was anticipated and attributed to the normal pancreas in FoCHI, it was paradoxical in DiCHI. Our in vitro results provide an explanation in showing that high glucose acutely stimulates insulin secretion from at least some focal lesions and DiCHI pancreas. The lack of a sustained second phase and of any stimulatory effect of a graded increase in glucose concentration in vitro is also compatible with in vivo observations in a single, nonoperated, older DiCHI patient (54).

The acute insulin response to calcium has been used to distinguish $\mathrm{CHI}$ due to $\mathrm{K}_{\mathrm{ATP}}$ channel mutations from other forms (peripheral i.v. calcium injection with modest elevation of calcemia) and to localize a focal lesion in the pancreas by selective arterial calcium stimulation of the pancreas with hepatic venous sampling (ASVS) $(30,32,33,53)$. The test is based on the expectation of a larger calcium influx (hence of insulin secretion) in $\beta$ cells that are depolarized because of the absence of $\mathrm{K}_{\mathrm{ATP}}$ channels (5). Our in vitro data obtained with a high $\mathrm{CaCl}_{2}$ concentration are relevant to the ASVS only. We observed that high $\mathrm{CaCl}_{2}$ induced insulin secretion not only from $\mathrm{CHI}$ pancreas but also from normal pancreas, which is explainable by the fact that the physiological glucose concentration of $5 \mathrm{mM}$ used in our in vitro experiments is stimulatory for normal $\beta$ cells. At best, a quantitative difference in the responses could be expected in vivo when the normal pancreas is not stimulated by glucose.

Genotype-phenotype correlations. As already emphasized, insulin secretory responses of the normal pancreas from FoCHI subjects were qualitatively similar to those of normal adult islets. This means that an inactivating mutation of $A B C C 8$ (or KCNJ11) in only 1 allele does not alter $\beta$ cell function. Our conclusion extends 2 in vivo studies showing that heterozygous carriers of an $A B C C 8$ mutation (one of which is Val187Asp as in our subjects FoCHI2, -3, and -4) normally secreted insulin in response to glucose or tolbutamide $(54,55)$. Half the number of functional $K_{A T P}$ channels would thus seem sufficient to ensure normal control of insulin secretion.
The genetic basis of FoCHI and DiCHI is different. Notably, owing to the loss of maternal CDKN1C (p57) and H19, and unrestrained expression of paternal IGF-II, focal lesions are characterized by an increased proliferation rate, as shown by Ki-67 immunodetection in approximately $8 \%$ of $\beta$ cells within the lesion as compared with approximately $3 \%$ in DiCHI or normal pancreas (56). In spite of these differences, the alterations of insulin secretion were similar in FoCHI and DiCHI pancreas.

The functional impact of 6 of the $A B C C 8$ mutations found in our patients has previously been evaluated by expression studies (Table 1). The mutation identified in subjects FoCHI2, -3, and -4 (57) abolishes $\mathrm{K}_{\mathrm{ATP}}$ channel expression at the plasma membrane by causing SUR1 retention in the endoplasmic reticulum (57-59). In these 3 cases, the paradoxical decrease in insulin secretion in response to glucose and increase in response to diazoxide were not observed. However, cases with another mutation also causing intracellular channel retention (FoCHI6 and DiCHI1, and DiCHI5) $(60,61)$ did show the paradoxical response to diazoxide. Except for the fact that high glucose did not decrease insulin secretion in DiCHI1, the responses of all $6 \mathrm{DiCHI}$ patients were similar in spite of different mutations. In one case (DiCHI4), the dominant mutation allows membrane expression (84\%) of a quasi-nucleotide-insensitive $K_{\text {ATP }}$ channel (62), but no difference in insulin secretion was observed with mutations causing complete inhibition of channel trafficking. Finally, no specific alteration of insulin secretion characterized the pancreas of the single patient with a mutation in KCNJ11 (FoCHI1). With the limitations imposed by the small number of possible comparisons in our group comprising only diazoxide-resistant $\mathrm{CHI}$ patients, this in vitro study shows that the ultimate impact on insulin secretion is determined by the lack of functional $\mathrm{K}_{\mathrm{ATP}}$ channels at the plasma membrane rather than the underlying genetic/cellular cause of this lack.

Conclusions. The sole presence of a paternal mutation in ABCC8 or KCNJ11 does not alter in vitro insulin secretion by the pancreas outside the lesion in FoCHI. Compared with normal pancreas, insulin content is very high in focal lesion and normal in DiCHI pancreas, but fractional insulin secretion is not particularly elevated in either pathological tissue at physiological glucose levels. However, qualitative perturbations are major and similar in the focal lesion and DiCHI pancreas despite their distinct genetic and cellular pathogeny. The in vitro insulin secretion rate is abnormally elevated in the presence of low glucose and virtually not increased by high glucose concentrations. Most surprising are the increase in secretion produced by diazoxide and the decrease sometimes caused by high glucose concentrations. Neither of these changes was reported in mouse islets lacking $\mathrm{K}_{\mathrm{ATP}}$ channels, and neither can be explained by current models of $\beta$ cells.

\section{Methods}

CHI subjects. The present study was conducted with the approval of and according to the regulations of the Commission d'Ethique Biomédicale of the University of Louvain Faculty of Medicine. Informed consent was obtained from the parents of the children.

The diagnosis of CHI was established on the basis of widely accepted criteria (1). The patients underwent partial or subtotal pancreatectomy because diazoxide and other medical measures proved inefficient to prevent hypoglycemia. Between 2000 and 2009, 30 cases of diazoxide-resistant CHI were included in the study, but only 18 FoCHI and 6 DiCHI cases could be retained in the final analysis (Table 1 ). 
In FoCHI, mean age at surgery was 6.4 (range 2-11) months. All patients were cured after resection of the focal lesion, sometimes after 2 or 3 operations (Table 1). Four additional subjects were studied but could not be included in the present analysis. In 2 patients, no control tissue was available for comparison with the responses measured in their focal lesion. In the other 2 , the fragments of focal lesion were largely contaminated with normal tissue as shown by low insulin content and microscopic evidence that the lesion was poorly delineated.

In DiCHI, mean age at surgery was 4.7 (range 2.5-7) months for 5 patients and 18 months in the sixth patient. Hypoglycemias persisted in 1 patient, and diabetes followed pancreatectomy in the others. Two further subjects could not be included in the study because the insulin content of the pancreatic fragments was too low ( $<10 \%$ of that in other cases) for reliable measurement of insulin secretion.

Genetic studies (authorized in 23/24 subjects) showed that 22 patients had a mutation in ABCC8 (19 different types) and only 1 in KCNJ11 (Table 1). Seven of these mutations are believed to be novel, and the others have previously been described $(6,7)$. Note that patient DiCHI1 is the sister of FoCHI6 (63) and that patient DiCHI6 is a compound heterozygote.

Postoperative morphological study of the pancreas. Pancreatic samples were fixed in Bouin solution for conventional microscopy and immunohistochemical identification of insulin-containing cells as described elsewhere (17). Other samples were fixed in $4 \%$ formalin to perform CDKN1C peptide immunodetection (anti-CDKN1C from NeoMarkers; dilution 1/100).

Sampling and treatment of pancreatic fragments for functional studies. On the basis of intraoperative examinations of frozen samples, the pathologist distinguished between FoCHI and DiCHI, directed the extent of pancreas resection, and sampled fragments for functional studies. Because great care was taken to avoid overlap of normal and pathological regions in FoCHI, available fragments were sometimes very small: average of $102 \mathrm{mg}$ (range 23-295) of normal pancreas and of $54 \mathrm{mg}$ (range 17-92) of focal lesion. Larger fragments were available from the pancreas of DiCHI patients in whom pancreatectomy was subtotal: average of $682 \mathrm{mg}$ (range 419-1092) of whole pancreas. Pancreatic fragments were immersed in sterile RPMI culture medium and transported at $4{ }^{\circ} \mathrm{C}$ to the laboratory in Brussels within 4-8 hours.

On arrival, each fragment was injected with $6 \mathrm{ml}$ of a salt-balanced medium containing $12 \mathrm{mg}$ collagenase, finely minced, and transferred into a tight tube. The suspension of tissue was then shaken by hand for about 3-4 minutes in a water bath at $37^{\circ} \mathrm{C}$, gently centrifuged for a few seconds, and rinsed several times at room temperature. Finally, the digested tissue consisting of clusters of cells and debris was resuspended in RPMI culture medium containing $5 \mathrm{mM}$ glucose, $100 \mathrm{IU}$ penicillin $/ \mathrm{ml}, 100 \mu \mathrm{g}$ streptomycin $/ \mathrm{ml}$, and $10 \%$ heat-inactivated fetal calf serum, and distributed into $3 \mathrm{~cm}$ petri dishes containing a final volume of $2 \mathrm{ml}$. Insulin secretion was studied the next day, after $17-22$ hours of culture at $37^{\circ} \mathrm{C}$, in an atmosphere of $5 \% \mathrm{CO}_{2}$ in air.

Measurements of insulin secretion. On the day of the experiment, an aliquot of culture medium was saved for insulin determination. Pancreatic tissue was then harvested from culture dishes and distributed into equivalent portions that were transferred into perifusion chambers. Details on the system, technique, and solutions can be found elsewhere $(26,64)$. At the end of an experiment, pancreatic tissue was recovered from the chambers for measurement of insulin content (65). Insulin in perifusion samples, tissue extracts, and culture medium was measured by radioimmunoassay using human insulin as a standard (26).

Expression of results. Because the amount of tissue placed in perifusion chambers was variable and because this tissue was heterogeneous, insulin secretion rate was expressed relative to the tissue insulin content (fractional insulin secretion as percentage of insulin content $/ \mathrm{min}$ ) (64). Insulin secretion by focal lesion and healthy pancreas of the same patient was directly compared in paired experiments. However, not all protocols could be done in each case because of limited tissue availability. Insulin content of fresh tissue was not measured because this would have reduced even further the amount of tissue for functional studies, but it was estimated as follows: to the insulin content of all tissue fragments from a patient (measured at the end of perifusions), we added the amount of insulin secreted by these fragments during perifusion and culture. From that sum and the weight of the fragment, the initial insulin content of the tissue could be recalculated. Two opposite sources of error are the loss of insulin during tissue mincing and digestion, and insulin biosynthesis during culture.

All values are presented as mean \pm SEM for the indicated number of experiments (patients) or with the range in parentheses. Statistical significance $(P<0.05)$ of changes in secretion was assessed by 2 -tailed Student's paired $t$ test, comparing values before and during application of test agent in the same preparation or values in normal and pathological tissue from the same subject.

\section{Acknowledgments}

This work was supported, over a 10-year period, by grants from the Fonds de la Recherche Scientifique et Médicale, Brussels, and from the Direction de la Recherche Scientifique de la Communauté Française de Belgique. We thank F. Knockaert (University of Louvain Faculty of Medicine) for technical help. We are grateful to R. Rooman (University Hospital, Antwerp, Belgium) and C. Dionisi-Vici and J. DeVille de Goyet (Bambino Gesù Children's Hospital, Rome, Italy) for each referring one patient. We also thank F. Brunelle, F. Jaubert, J.M. Saudubray, and V. Verkarre (Hospital Necker) for contributions to clinical evaluation of the patients in Paris, and C. Junien (Hospital Necker) and C. Saint-Martin and C. Vaury (Hospital Pitié-Salpétrière) for contributions to molecular analysis.

Received for publication April 7, 2011, and accepted in revised form July 13, 2011.

Address correspondence to: Jean-Claude Henquin, Unit of Endocrinology and Metabolism, UCL 55.30, Avenue Hippocrate 55, B-1200 Brussels, Belgium. Phone: 32.2.7645529; Fax: 32.2.7645532; E-mail: jean-claude.henquin@uclouvain.be.
1. De León DD, Stanley CA. Mechanisms of Disease: advances in diagnosis and treatment of hyperinsulinism in neonates. Nat Clin Pract Endocrinol Metab. 2007;3(1):57-68.

2. James C, Kapoor RR, Ismail D, Hussain K. The genetic basis of congenital hyperinsulinism. J Med Genet. 2009;46(5):289-299.

3. Nestorowicz A, et al. Genetic heterogeneity in familial hyperinsulinism. Hum Mol Genet. 1998; 7(7):1119-1128.

4. Aguilar-Bryan L, Bryan J. Molecular biology of adenosine triphosphate-sensitive potassium channels. Endocr Rev. 1999;20(2):101-135.
5. Dunne MJ, Cosgrove KE, Shepherd RM, AynsleyGreen A, Lindley KJ. Hyperinsulinism in infancy: from basic science to clinical disease. Physiol Rev. 2004;84(1):239-275.

6. Flanagan SE, et al. Update of mutations in the genes encoding the pancreatic beta-cell K(ATP) channel subunits Kir6.2 (KCNJ11) and sulfonylurea receptor $1(A B C C 8)$ in diabetes mellitus and hyperinsulinism. Hum Mutat. 2009;30(2):170-180.

7. Bellanné-Chantelot C, et al. ABCC8 and KCNJ11 molecular spectrum of 109 patients with diazoxide-unresponsive congenital hyperinsulinism. JMed Genet. 2010;47(11):752-759.
8. Henquin JC. Regulation of insulin secretion: a matter of phase control and amplitude modulation. Diabetologia. 2009;52(5):739-751.

9. Henquin JC. Pathways in $\beta$-cell stimulus-secretion coupling as targets for therapeutic insulin secretagogues. Diabetes. 2004;53 suppl 3:S48-S58.

10. Rahier J, Fält K, Müntefering H, Becker K, Gepts W, Falkmer S. The basic structural lesion of persistent neonatal hypoglycaemia with hyperinsulinism: deficiency of pancreatic D cells or hyperactivity of B cells? Diabetologia. 1984;26(4):282-289.

11. Sempoux C, et al. Neonatal hyperinsulinemic hypoglycemia: heterogeneity of the syndrome and keys 
for differential diagnosis. J Clin Endocrinol Metab. 1998;83(5):1455-1461.

12. Thomas PM, et al. Mutations in the sulfonylurea receptor gene in familial persistent hyperinsulinemic hypoglycemia of infancy. Science. 1995;268(5209):426-429.

13. Thomas P, Ye Y, Lightner E. Mutation of the pancreatic islet inward rectifier Kir6.2 also leads to familial persistent hyperinsulinemic hypoglycemia of infancy. Hum Mol Genet. 1996;5(11):1809-1812.

14. Verkarre V, et al. Paternal mutation of the sulfonylurea receptor (SUR1) gene and maternal loss of 11 p15 imprinted genes lead to persistent hyperinsulinism in focal adenomatous hyperplasia. J Clin Invest. 1998;102(7):1286-1291.

15. Damaj L, et al. Chromosome $11 \mathrm{p} 15$ paternal isodisomy in focal forms of neonatal hyperinsulinism. J Clin Endocrinol Metab. 2008;93(12):4941-4947.

16. Kassem SA, et al. p57(KIP2) expression in normal islet cells and in hyperinsulinism of infancy. Diabetes. 2001;50(12):2763-2769.

17. Sempoux C, et al. The focal form of persistent hyperinsulinemic hypoglycemia of infancy: morphological and molecular studies show structural and functional differences with insulinoma. Diabetes. 2003;52(3):784-794

18. de Lonlay $\mathrm{P}$, et al. Somatic deletion of the imprinted $11 \mathrm{p} 15$ region in sporadic persistent hyperinsulinemic hypoglycemia of infancy is specific of focal adenomatous hyperplasia and endorses partial pancreatectomy. J Clin Invest. 1997;100(4):802-807.

19. Rahier J, et al. Partial or near-total pancreatectomy for persistent neonatal hyperinsulinaemic hypoglycaemia: the pathologist's role. Histopathology. 1998;32(1):15-19.

20. Kane C, et al. Loss of functional KATP channels in pancreatic $\beta$-cells causes persistent hyperinsulinemic hypoglycemia of infancy. Nat Med. 1996;2(12):1344-1347.

21. Straub SG, et al. Hyperinsulinism of infancy: the regulated release of insulin by KATP channel-independent pathways. Diabetes. 2001;50(2):329-339.

22. Cosgrove KE, et al. BPDZ 154 activates adenosine 5 '-triphosphate-sensitive potassium channels: in vitro studies using rodent insulin-secreting cells and islets isolated from patients with hyperinsulinism. J Clin Endocrinol Metab. 2002;87(11):4860-4868.

23. Aynsley-Green A, et al. Nesidioblastosis of the pancreas: definition of the syndrome and the management of the severe neonatal hyperinsulinaemic hypoglycaemia. Arch Dis Child. 1981;56(7):496-508.

24. Otonkoski T, Andersson S, Simell O. Somatostatin regulation of $\beta$-cell function in the normal human fetuses and in neonates with persistent hyperinsulinemic hypoglycemia. J Clin Endocrinol Metab. 1993;76(1):184-188.

25. Kaiser N, et al. Regulation of insulin release in persistent hyperinsulinaemic hypoglycaemia of infancy studied in long-term culture of pancreatic tissue. Diabetologia. 1990;33(8):482-488.

26. Henquin JC, Dufrane D, Nenquin M. Nutrient control of insulin secretion in isolated normal human islets. Diabetes. 2006;55(12):3470-3477.

27. Garrino MG, Plant TD, Henquin JC. Effects of putative activators of $\mathrm{K}+$ channels in mouse pancreatic $\beta$-cells. BrJ Pharmacol. 1989;98(3):957-965.

28. Szollosi A, Nenquin M, Henquin JC. Pharmacological stimulation and inhibition of insulin secretion in mouse islets lacking ATP-sensitive $\mathrm{K}^{+}$channels. BrJ Pharmacol. 2010;159(3):669-677.

29. Detimary P, Gilon P, Nenquin M, Henquin JC. Two sites of glucose control of insulin release with distinct dependence on the energy state in pancreatic B-cells. Biochem J. 1994;297(pt 3):455-461.

30. Ferry RJ Jr, et al. Calcium-stimulated insulin secretion in diffuse and focal forms of congenital hyperinsulinism. J Pediatr. 2000;137(2):239-246.

31. Huopio $\mathrm{H}$, et al. Acute insulin response tests for the differential diagnosis of congenital hyperinsulinism. J Clin Endocrinol Metab. 2002;87(10):4502-4507.

32. Giurgea I, et al. Acute insulin responses to calcium and tolbutamide do not differentiate focal from diffuse congenital hyperinsulinism. J Clin Endocrinol Metab. 2004;89(2):925-929.

33. Stanley CA, et al. Preoperative evaluation of infants with focal or diffuse congenital hyperinsulinism by intravenous acute insulin response tests and selective pancreatic arterial calcium stimulation. J Clin Endocrinol Metab. 2004;89(1):288-296.

34. Mourad NI, Nenquin M, Henquin JC. Metabolic amplifying pathway increases both phases of insulin secretion independently of $\beta$-cell actin microfilaments. Am J Physiol Cell Physiol. 2010; 299(2):C389-C398.

35. Braun M, et al. Somatostatin release, electrical activity, membrane currents and exocytosis in human pancreatic delta cells. Diabetologia. 2009;52(8):1566-1578.

36. Grimmsmann T, Rustenbeck I. Direct effects of diazoxide on mitochondria in pancreatic B-cells and on isolated liver mitochondria. Br J Pharmacol. 1998;123(5):781-788.

37. Miki T, et al. Defective insulin secretion and enhanced insulin action in KATP channel-deficient mice. Proc Natl Acad Sci U S A. 1998;95(18):10402-10406.

38. Seghers V, Nakazaki M, DeMayo F, Aguilar-Bryan L, Bryan J. Sur1 knockout mice. A model for K(ATP) channel-independent regulation of insulin secretion. J Biol Chem. 2000;275(13):9270-9277.

39. Shiota C, Rocheleau JV, Shiota M, Piston DW, Magnuson MA. Impaired glucagon secretory responses in mice lacking the type 1 sulfonylurea receptor. $A m$ J Physiol Endocrinol Metab. 2005;289(4):E570-E577.

40. De León DD, Li C, Delson MI, Matschinsky FM, Stanley CA, Stoffers DA. Exendin-(9-39) corrects fasting hypoglycemia in SUR-1//- mice by lowering cAMP in pancreatic $\beta$-cells and inhibiting insulin secretion. J Biol Chem. 2008;283(38):25786-25793.

41. Miki T, et al. ATP-sensitive potassium channels participate in glucose uptake in skeletal muscle and adipose tissue. Am J Physiol Endocrinol Metab. 2002;283(6):E1178-E1184.

42. Nenquin M, Szollosi A, Aguilar-Bryan L, Bryan J, Henquin JC. Both triggering and amplifying pathways contribute to fuel-induced insulin secretion in the absence of sulfonylurea receptor- 1 in pancreatic $\beta$-cells. J Biol Chem. 2004;279(31):32316-32324

43. Ravier MA, Nenquin M, Miki T, Seino S, Henquin JC. Glucose controls cytosolic $\mathrm{Ca}^{2+}$ and insulin secretion in mouse islets lacking adenosine triphosphate-sensitive $\mathrm{K}^{+}$channels owing to a knockout of the pore-forming subunit Kir6.2. Endocrinology. 2009;150(1):33-45

44. Doliba NM, et al. Restitution of defective glucosestimulated insulin release of sulfonylurea type 1 receptor knockout mice by acetylcholine. Am J Physiol Endocrinol Metab. 2004;286(5):E834-E843.

45. Szollosi A, Nenquin M, Aguilar-Bryan L, Bryan $\mathrm{J}$, Henquin JC. Glucose stimulates $\mathrm{Ca}^{2+}$ influx and insulin secretion in 2-week-old $\beta$-cells lacking ATP-sensitive $\mathrm{K}^{+}$channels. J Biol Chem. 2007;282(3):1747-1756

46. Fujimoto W, et al. Niflumic acid-sensitive ion channels play an important role in the induction of glucose-stimulated insulin secretion by cyclic AMP in mice. Diabetologia. 2009;52(5):863-872.

47. Doliba NM, et al. Cholinergic regulation of fuelinduced hormone secretion and respiration of SUR1-/- mouse islets. Am J Physiol Endocrinol Metab. 2006;291(3):E525-E535.

48. Szollosi A, Nenquin M, Henquin JC. Overnight culture unmasks glucose-induced insulin secretion in mouse islets lacking ATP-sensitive $\mathrm{K}^{+}$channels by improving the triggering $\mathrm{Ca}^{2+}$ signal. $\mathrm{J}$ Biol Chem. 2007;282(20):14768-14776.

49. Eliasson L, et al. SUR1 regulates PKA-independent
cAMP-induced granule priming in mouse pancreatic B-cells. J Gen Physiol. 2003;121(3):181-197.

50. Haspel D, Krippeit-Drews P, Aguilar-Bryan L, Bryan J, Drews G, Düfer M. Crosstalk between membrane potential and cytosolic $\mathrm{Ca}^{2+}$ concentration in beta cells from Sur1 $1^{-/-}$mice. Diabetologia. 2005;48(5):913-921.

51. Li C, et al. A signaling role of glutamine in insulin secretion. J Biol Chem. 2004;279(14):13393-13401.

52. Li C, et al. Elimination of $\mathrm{K}_{\mathrm{ATp}}$ channels in mouse islets results in elevated $\left[\mathrm{U}-{ }^{13} \mathrm{C}\right]$ glucose metabolism, glutaminolysis, and pyruvate cycling but a decreased gamma- aminobutyric acid shunt. J Biol Chem. 2008;283(25):17238-17249.

53. Henwood MJ, et al. Genotype-phenotype correlations in children with congenital hyperinsulinism due to recessive mutations of the adenosine triphosphate-sensitive potassium channel genes. J Clin Endocrinol Metab. 2005;90(2):789-794.

54. Grimberg A, et al. Dysregulation of insulin secretion in children with congenital hyperinsulinism due to sulfonylurea receptor mutations. Diabetes. 2001;50(2):322-328.

55. Huopio H, Vauhkonen I, Komulainen J, Niskanen L, Otonkoski T, Laakso M. Carriers of an inactivating $\beta$-cell ATP-sensitive $\mathrm{K}^{+}$channel mutation have normal glucose tolerance and insulin sensitivity and appropriate insulin secretion. Diabetes Care. 2002;25(1):101-106.

56. Sempoux C, et al. Pancreatic B-cell proliferation in persistent hyperinsulinemic hypoglycemia of infancy: an immunohistochemical study of 18 cases. Mod Pathol. 1998;11(5):444-449.

57. Otonkoski $\mathrm{T}$, et al. A point mutation inactivating the sulfonylurea receptor causes the severe form of persistent hyperinsulinemic hypoglycemia of infancy in Finland. Diabetes. 1999;48(2):408-415.

58. Chan KW, Zhang H, Logothetis DE. N-terminal transmembrane domain of the SUR controls trafficking and gating of Kir6 channel subunits. $E M B O J$. 2003;22(15):3833-3843

59. Yan F, Lin CW, Weisiger E, Cartier EA, Taschenberger G, Shyng SL. Sulfonylureas correct trafficking defects of ATP-sensitive potassium channels caused by mutations in the sulfonylurea receptor. J Biol Chem. 2004;279(12):11096-11105.

60. Muzyamba M, et al. Complex ABCC8 DNA variations in congenital hyperinsulinism: lessons from functional studies. J Clin Endocrinol. 2007; 67(1):115-124

61. Tornovsky S, et al. Hyperinsulinism of infancy: novel $A B C C 8$ and $K C N J 11$ mutations and evidence for additional locus heterogeneity. J Clin Endocrinol Metab. 2004;89(12):6224-6234.

62. MacMullen CM, et al. Diazoxide-unresponsive congenital hyperinsulinism in children with dominant mutations of the $\beta$-cell sulfonylurea receptor SUR1. Diabetes. 2011;60(6):1797-1804.

63. Valayannopoulos V, et al. Coexistence in the same family of both focal and diffuse forms of hyperinsulinism. Diabetes Care. 2007;30(6):1590-1592.

64. Henquin JC, Nenquin M, Stiernet P, Ahren B. In vivo and in vitro glucose-induced biphasic insulin secretion in the mouse: pattern and role of cytoplasmic Ca2+ and amplification signals in $\beta$-cells. Diabetes. 2006;55(2):441-451.

65. Detimary P, Jonas JC, Henquin JC. Stable and diffusible pools of nucleotides in pancreatic islet cells. Endocrinology. 1996;137(11):4671-4676.

66. De Vroede M, Bax NM, Brusgaard K, Dunne MJ, Groenendaal F. Laparoscopic diagnosis and cure of hyperinsulinism in two cases of focal adenomatous hyperplasia in infancy. Pediatrics. 2004; 114(4):e520-e522.

67. Powell PD, et al. In vitro recovery of ATP-sensitive potassium channels in beta-cells from patients with congenital hyperinsulinism of infancy. Diabetes. 2011;60(4):1223-1228 